\title{
A ESTRUTURA DA LÓGICA SEGUNDO TOMÁS DE AQUINO
}

\author{
Anselmo Tadeu Ferreira*
}

\begin{abstract}
RESUMO
Neste artigo fazemos uma apresentação em pormenor do prólogo do comentário de Tomás de Aquino aos Segundos Analíticos de Aristóteles, a Expositio libri Posteriorum. Neste prólogo, isto é, uma introdução à exposição de tipo literal que Tomás empreenderá em seguida, o autor situa a obra Segundos Analíticos na estrutura da lógica. Ao fazer isso, ele apresenta, de um modo que em nenhuma outra obra ele expressou com igual clareza, sua própria concepção da lógica em geral, o modo como esta disciplina se caracteriza ora como arte ora como ciência e como ela se relaciona aos processos do espírito humano, do intelecto e da razão e como essa estrutura corresponde ao conjunto das obras lógicas de Aristóteles.
\end{abstract}

Palavras-chave: Filosofia medieval. Lógica medieval. Tomás de Aquino.

\begin{abstract}
We intend to present in detail the prologus of the Thomas Aquinas' commentary on Aristotle's Posterior Analytics, the Expositio libri Posteriorum. In this prologus, that is, an introduction to the literal exposition which is to be made, the author situates Posterior Analytics in the structure of the Logic as a discipline. Making this, he presents, in a manner which he didn't treat this anywhere, his proper account of logic in general, the way how this discipline is characterized as an art or as a science and how it is related to the process of human spirit, intellect and reason and how this structure corresponds to the Aristotelian opus known as the Organum
\end{abstract}

Keywords: Medieval philosophy. Medieval logic.Thomas Aquinas.

\footnotetext{
* Doutor em Filosofia pela Universidade Estadual de Campinas (UNICAMP). Professor do Instituto de Filosofia da Universidade Federal de Uberlândia (UFU). E-mail: anselmotf@superig.com.br
} 


\section{Introdução}

Pretendemos apresentar neste trabalho a concepção de Tomás de Aquino sobre a lógica, tal como ele a apresenta no seu comentário aos Segundos Analíticos, de Aristóteles. Nesta obra, dedicada a uma exposição detalhada da obra aristotélica sobre o silogismo demonstrativo, Tomás escreve uma introdução, da qual falaremos mais adiante, na qual ele faz uma descrição sobre a estrutura da lógica. Podemos perceber, como critérios norteadores dessa estrutura, a relação da lógica com os atos ou operações do intelecto humano e a relação desses atos com os escritos aristotélicos.

$\mathrm{Na}$ caracterização dos atos ou operações do intelecto humano, é de se notar a distinção feita por Tomás entre intelecto e razão, que serve como pano de fundo para toda a caracterização da lógica e de suas partes constituintes e tem como fundamento a concepção de Tomás de Aquino sobre o conhecimento humano, tal como também aparece na Suma de Teologia, no comentário ao De Trinitate, de Boécio e no opúsculo $O$ ente e a essência.

Nosso trabalho prático consistirá, portanto, em uma apresentação do prólogo do comentário de Tomás de Aquino aos Segundos Analíticos, que recebeu dos editores o título de Expositio libri Posteriorum, ajuntando a essa apresentação reflexões baseadas nas demais obras de Tomás acima citadas que ajudam a situar a problemática do conhecimento humano num quadro mais amplo. No final do texto, apresentamos, como anexo, a tradução do referido prólogo quanto à parte que nos interessa.

\section{A Expositio Libri Posteriorum}

No dia 2 de maio de 1274, os mestres da Faculdade de Artes da Universidade de Paris, representados pelo próprio reitor da universidade, escreveram uma carta que deveria ser lida pelos frades dominicanos reunidos em Lião, no dia 20 do mesmo mês, em seu capítulo geral ${ }^{1}$. Com

1 O texto latino desta carta foi publicado por Birkenmajer, A. "Der Brief der Pariser Artistenfakultät über den Tod des hl. Thomas von Aquin” em Beiträge zur Geschichte 
palavras veementes, os mestres de Paris manifestavam o seu grande pesar pela morte de Tomás de Aquino, frade dominicano e mestre de teologia em Paris, ocorrida em 7 de março daquele ano. Tomás, que havia deixado Paris em abril de 1272, e desde então ensinara na Itália, morreu em plena atividade intelectual, deixando incompleta a Suma de Teologia e provavelmente alguns projetos a realizar, dentre os quais, alguns comentários de obras aristotélicas.

Na referida carta, após lamentar profundamente o falecimento do frei Tomás, a "estrela d'alva do mundo", o "esplendor e luz do século", "o luminar maior que presidia ao dia", e comparar sua morte a um tenebroso eclipse que tivesse afetado toda a Cristandade - os mestres solicitam aos frades o traslado dos restos mortais do professor para que fosse inumado no lugar mais digno, isto é, na própria Universidade de Paris "que primeiro o alimentou e educou e depois dele próprio recebeu alimento e cuidados".

Além disso, os mestres aproveitam a ocasião para solicitar o envio de algumas obras que Tomás estava escrevendo quando deixou Paris e que certamente terminara na Itália. Referem-se especificamente a obras relacionadas com a lógica, que ele começara a escrever a seu pedido, além de outros livros que não seriam de autoria de Tomás, mas que este lhes prometera enviar da Itália² .

A menção aos livros de lógica nessa carta refere-se, com muita probabilidade, aos comentários aos Segundos Analíticos e ao Peri Hermeneias, de Aristóteles ${ }^{3}$. Esse último, de fato permaneceu inconcluso,

der Philosophie des Mittelalters, Munique, v. 20, fasc. 5, p. 1-35. O texto encontra-se nas páginas 2-5 e a tradução por nós utilizada é de Carlos Arthur Ribeiro do Nascimento (inédita).

2 "Ceterum sperantes, quod obtemperentis nobis cum effectu hac petictione devota, humiliter suplicamus, ut cum quaedam scripta ad philosophiam spectancia, Parisius inchoata ab eo, in suo recessu relinquerit imperfecta, et ipsum credamus ea, ubi translatus fuerat, complevisse nobis benevolencia vestra cito communicari procuret (...) ad logicam pertinentia composuit - sicut quando recessit a nobis humiliter petivimus ab eodem - ea vestra benignitas nostro communicare collegio dignetur" (Idem, ibidem).

${ }^{3}$ AQUINO, T. de. Opera Omnia iussu Leonis XIII P.M. Roma: Comissio Leonina; Paris: Librairie Philosophique J. Vrin, 1989. Editio altera retractata, cura et studio Fratrum Praedicatotum. A Expositio Peri Hermeneias encontra-se no volume I-1 e 
(Tomás comentou apenas o livro I na divisão medieval), mas o primeiro foi concluído por Tomás e, depois de uma longa tradição de cópias manuscritas e edições antigas, chegou até nós em sua edição mais recente na edição Leonina, a edição crítica de 1989.

O comentário de Tomás de Aquino aos Segundos Analíticos é, portanto, uma das últimas obras escritas por ele. $\mathrm{O}$ editor da edição Leonina, com base em elementos internos do texto e no testemunho da carta dos mestres de Paris ao Capítulo Dominicano, está seguro em dar como data de sua realização os anos de 1272-1274, os últimos anos de vida de Tomás, na Itália, embora ele tenha começado a redigi-lo ainda em Paris, como pode se depreender da referida carta.

Havia cinquenta anos que o texto dos Segundos Analíticos de Aristóteles penetrara nas fronteiras da universidade medieval. A dificuldade representada por essa obra, seja por causa do seu assunto seja por seu estilo extremamente conciso, motivava os que estavam na linha de frente do trabalho filosófico a lidar com ele, para procurar apresentá-lo de modo mais fácil aos menos afortunados. Ao realizar o seu comentário, Tomás se inscreve em uma antiga tradição que começa com os autores gregos, como Alexandre de Afrodísia, Temístio e Eustrátio, passa pelos árabes e finalmente atinge os contemporâneos de Tomás. O primeiro autor latino a comentar o texto na Baixa Idade Média parece ter sido Roberto Grosseteste. Após ele, Alberto Magno, mestre de Tomás, também escreveu o seu comentário. O comentário de Tomás é, na verdade, uma exposição literal (expositio litterae) e nisso ele é diferente dos comentários de seus sucessores, que parecem mais preocupados em expandir a reflexão sobre os temas apresentados do que apresentá-los de um modo didático. A exposição literal é um comentário linha por linha, exaustivo, mas que não se afasta muito do texto original, já que o objetivo é mais didático do que filosófico, procura-se antes dar um entendimento literal do texto mais do que discutir suas teses com alguma profundidade.

A estrutura do comentário de Tomás de Aquino aos Segundos Analíticos de Aristóteles é um exemplo típico daquilo que Olga Weijers

a Expositio libri Posteriorum, no volume I-2, ambos com prefácio de René Antoine Gauthier, que é o responsável pela edição. A alusão à carta dos mestres parisienses está na página $77^{*}$, do prefácio ao volume I-2. 
chama de comentário parisiense ${ }^{4}$, e o que mais chama a atenção é a presença daquelas "monstruosas divisiones litterae" de que fala Ebbesen 5 . Todos os elementos estão aí: o texto é sistematicamente dividido, com indicações tão precisas, que foi possível ao editor identificar a versão ou versões do texto aristotélico utilizadas. Apresenta-se a intenção do autor previamente à exposição literal.

Como forma de explicitar a estrutura do texto, o expositor intervém a todo o momento neste, fazendo observações de toda ordem, formulando e solucionando dúvidas e aparentes contradições com outros textos de Aristóteles e especialmente mobilizando a literatura sobre o texto, utilizando-se de comentários já existentes (no caso, os de Temístio, Averrois, Roberto Grosseteste e Alberto Magno).

\section{O prólogo}

Exatamente por seu propósito didático, o comentário se faz introduzir por um prólogo. Um prólogo é uma peça literária, que, colocada no início da obra, tem como objetivo facilitar a leitura do que vem a seguir. Isso pode ser feito de muitas maneiras, seja situando a obra num contexto mais amplo, seja esclarecendo noções preliminares. Tomás escreveu muitos comentários de obras aristotélicas e para todas elas escreveu prólogos. Nas edições mais antigas da obra, como a edição Marietti ${ }^{6}$, por exemplo, o prólogo é destacado do comentário, constituindo um capítulo separado. Na edição Leonina ${ }^{7}$, que utilizaremos em nossas considerações, ele é parte do capítulo 1, embora as páginas que o contém tenham a indicação "proemium".

\footnotetext{
${ }^{4}$ WEIJERS, O. La Structure des commentaires philosophiques à la faculté des arts: quelques observations. In: Brepols: Turnhout, 2002. p. 17-41. . Il commento filosofico nell'ocidente latino,

5 EBBESEN, S. Late ancient ancestors of medieval philosophical commentaries. In: Il commento filosofico nell'ocidente latino, Brepols: Turnhout, 2002. p. 1-15.

${ }^{6}$ AQUINO, T. de. Aristotelis libros Peri hermeneias et Posteriorum analiticorum expositio. Milano: Casa Editrice Marietti, 1955.

${ }^{7}$ AQUINO, T. de. Opera Omnia iussu Leonis XIII P.M. Roma: Comissio Leonina; Paris: Librairie Philosophique J. Vrin, 1989. Editio altera retractata, cura et studio Fratrum Praedicatotum. Tomo I/2.
} 
Nessa introdução, Tomás faz uma caracterização da lógica em sua estrutura geral, identificando-a como a arte que dirige os atos da razão. Tendo os atos ou operações da razão como sua matéria de estudo, a lógica se articula de acordo com esses atos, que são três ou de três tipos: a simples apreensão ou apreensão dos incomplexos, a composição/divisão e o raciocínio. Em seguida, Tomás mostra a correspondência do estudo de cada um desses atos com as obras lógicas de Aristóteles.

Especial atenção é dada à parte judicativa da lógica (onde se encontra, entre outros, os Segundos Analíticos), em que os atos da razão são comparados aos atos da natureza. Há operações da natureza que são infalíveis, isto é, necessárias e há operações que são contingentes; no caso destas, a operação tanto pode atingir o resultado esperado, que é o que ocorre no mais das vezes, como pode falhar quanto a esse objetivo, devido a algum erro no processo. Assim, há um processo da razão que conduz a verdades necessárias e outros que conduzem a verdades contingentes. Assim, se distinguem, na lógica, a parte analítica, que conduz à certeza e a dialética, que conduz ao provável. E há também o estudo das falhas no processo de pensamento que podem conduzir ao erro. Todas essas partes são contempladas pelas obras aristotélicas que constituem o Organon, considerado por Tomás de Aquino, bem como por muitos pensadores medievais, uma obra definitiva.

Toda a parte judicativa da lógica, que compreende a analítica e os diversos graus da dialética (pois também a Retórica e a Poética são enquadradas por Tomás de Aquino dentro da estrutura das obras lógicas, pois consistem em estudos sobre tipos de argumentos persuasivos), tem como referência o terceiro ato ou processo da razão ou do espírito humano, que podemos chamar de discurso ou de razão em sentido estrito. Curiosamente, o prólogo da Expositio libri Posterioreum é um dos dois únicos textos em que Tomás identifica essa terceira operação do espírito. A tradição anterior identifica apenas duas operações, a simples apreensão e a composição/divisão, o próprio Tomás faz isso em textos anteriores ${ }^{8}$. O que ele chama de terceira operação, que é a capacidade do espírito

\footnotetext{
${ }^{8}$ Ver por exemplo a questão 84 da Suma de Teologia, parte I e o comentário ao De Trinitate.
} 
humano de discorrer, a partir do que já é conhecido, a fim de atingir o que é ignorado, era visto tradicionalmente como um caso da segunda operação, a composição/divisão.

A introdução dessa terceira operação põe em relevo a razão discursiva como uma capacidade própria do ser humano, resultante do seu equipamento cognoscente. Por sua natureza, o ser humano depende de uma colaboração entre o intelecto e os sentidos para conhecer o mundo ao redor de si, o que se dá por abstração. Já no primeiro processo, que é a apreensão do simples, essa colaboração é necessária, pois se o conhecimento do "o que é” da coisa exterior é produto intelectual, esse produto passa primeiro por uma apreensão dos caracteres sensíveis da coisa pelos nossos sentidos. É por causa dessa nossa dependência dos sentidos que a primeira operação e, portanto, a segunda, que depende dela, não pode ser infalível. Quanto à terceira, que depende das duas anteriores, também não é, em geral, infalível, embora o objetivo dos Segundos Analíticos pareça ser justamente descobrir em que condições nosso pensamento pode ser infalível.

\section{Lógica: arte das artes}

O ponto de partida da introdução geral sobre a lógica, feita no prólogo da Expositio, é a noção de arte, cuja definição é "certa ordenação da razão, de modo que, através de meios determinados se atinja o devido fim do ato humano" ". A capacidade de agir com arte e não meramente segundo o instinto é o caráter distintivo do ser humano em relação aos animais irracionais ${ }^{10}$.

Há, portanto, artes que nos orientam quanto a muitas de nossas ações, especialmente aquelas que dizem respeito às nossas necessidades: a carpintaria, a arquitetura, etc. Em todas as artes, é a razão que está dirigindo nossos atos. Ora, a razão é capaz também de considerar seus

9 “...nichil enim aliud ars esse videtur quam certa ordinatio rationis, quomodo per determinata media ad debitum finem actus humani perveniatur." (AQUINO, 1989, I, 1, 9-12). As traduções do texto são de nossa responsabilidade. Nas citações do texto latino, entenda-se: I, 1, 9-12, por exemplo, como: livro I, capítulo 1, linhas 9 a 12.

${ }^{10} \mathrm{Cf}$. ARISTÓTELES, Metafísica, A, 1. 
próprios atos e, por isso, deve haver uma arte que oriente os próprios atos da razão; a razão, refletindo sobre seus próprios atos, produz uma arte que orienta o próprio pensamento. Essa arte, que seria a "arte das artes", dado o seu caráter de anterioridade em relação às outras artes, é o que se chama a lógica. Ela garante que o ato da razão seja feito de modo ordenado, facilmente e sem erro ${ }^{11}$.

\section{As partes da lógica}

Além de apresentar a lógica como "arte das artes", o prólogo da Expositio também a qualifica como "ciência racional", não só em virtude do uso da razão, que é comum a todas as artes, mas por ser a razão a matéria de que trata; afinal é diretiva dos atos da razão ${ }^{12}$.

Tendo como matéria os atos da razão, o sujeito da ciência da lógica, o seu tema de estudo, terá de ser os atos da razão. Por isso, há uma divisão na lógica, que não é arbitrária ou simplesmente didática. A lógica se divide de acordo com a divisão dos atos da razão. Há uma arquitetura da lógica que é um espelho da arquitetura do pensamento e da razão humana. Cada parte da lógica refere-se a um elemento na estrutura da razão e cada um dos escritos do Organon recobre uma das partes da lógica.

Em primeiro lugar, há três partes da lógica porque há três operações do espírito: a inteligência dos indivisíveis, a composição/divisão e o raciocínio. Tomás ensina que os dois primeiros atos são da razão na medida em que esta é uma intelecção e apenas o terceiro é mais próprio da

\footnotetext{
${ }^{11}$ A expressão "arte das artes" parece ter surgido a partir do comentário ao texto da Metafísica A, 2, como lembra Gauthier nas notas da edição crítica (AQUINO, 1989, I, p. 4, notas). Os comentadores gregos (Amônio, Filopono, Elias, David e Eustrátio) a usavam como definição da filosofia ou da filosofia primeira e Roberto Grosseteste a identifica com a teologia. A expressão também foi usada na Idade Média por Isidoro, Damasceno, Macróbio, Cassiodoro, Gundissalino e Hugo de S. Vitor. Agostinho (De ordine II, XIII, 38) a utiliza com referência a uma parte da filosofia, que é a dialética, no que é louvado por Abelardo (Epístola 13) e João de Salisbury (Metalogicon, IV, 25), além de aparecer no tratado de Pedro Hispânico e nas Sumule dialetice de Roger Bacon. Todas as referências estão na nota citada da edição Leonina da Expositio.
}

${ }^{12}$ Cf. AQUINO, 1989, I, 1, 1-25. 
atividade racional, que consiste em passar do conhecido ao desconhecido ${ }^{13}$. À primeira operação do espírito é dedicado o livro das Categorias e à segunda o Peri Hermeneias (Sobre a Interpretação).

Caracterizemos essas operações, conforme o faz o próprio Tomás no seu comentário. A primeira operação consiste na simples apreensão do que é indivisível ou incomplexo. Esta intelecção (ou entendimento) do incomplexo concebe o que é a coisa. Trata-se, em outros termos, de "enformação do intelecto" ou de "imaginação pelo intelecto"14. Quanto à segunda operação, que constrói a partir dos inteligidos pela primeira, já há nela verdade/falsidade, pois se trata de composição ou divisão dos inteligidos ${ }^{15}$. Por composição, diz-se que algo é outro algo, por exemplo, na proposição "a neve é branca". Por divisão, diz-se que algo não é outro algo, por exemplo, "a neve não é azul". Estes enunciados complexos são suscetíveis de serem verdadeiros ou falsos, o que não acontecia com os indivisíveis ou incomplexos, como "neve", "branca" ou "azul".

A terceira operação do espírito é aquela a que são dedicados os demais escritos do Organon (Primeiros e Segundos Analíticos, Tópicos, Refutações Sofísticas, Retórica, Poética). Esta operação ou ato é introduzido por Tomás de Aquino com os seguintes termos: "No entanto, o terceiro ato da razão se dá de acordo com o que é próprio da razão, isto é, discorrer de um a outro, de modo que, por aquilo que é conhecido, chegue

\footnotetext{
${ }^{13}$ Segundo o que pudemos averiguar, esse é um dos dois únicos textos em que Tomás fala explicitamente em três operações do espírito. O outro é o comentário ao Peri Hermeneias (In Pery Herm I, 1,1) em que ele acrescenta uma terceira operação, o raciocínio, às duas que tradicionalmente são consideradas, a inteligência dos indivisíveis e a composição/divisão, conforme o texto aristotélico do De Anima III, 5. No próprio comentário de Tomás a esse texto (Sententia libri de Anima III, 5) não há qualquer alusão a uma terceira operação. Em nota à edição do In Peri Hemeneias, R. A. Gauthier diz que o acréscimo dessa terceira operação não foi feito por Aristóteles, que coloca a composição/divisão e o raciocínio no mesmo ato do intelecto ou operação do espírito.

14 "una enim actio intellectus est itelligencia indivisibilium, sive incomplexorum, secundum quam concipit quid est res, et hec operatio a quibusdam dicitur informatio intellectus sive ymaginatio per intelectum" (AQUINO, 1989, I, 1, 35-40).

15 "secunda vero operatio intellectus est compositio vel divisio intellectum, in qua est iam verum et falsum" (AQUINO, 1989, I, 1, 42-44).
} 
ao conhecimento do que é desconhecido"16.

A introdução dessa terceira operação liga-se à distinção entre "intellectus" e "ratio", palavras que eram sinônimas para os escritores antigos e na latinidade cristã. A distinção, que não é aristotélica nem boeciana, tem origem neoplatônica, especialmente no Pseudo Dionísio (De divinibus nominibus, $I V)^{17}$. Segundo essa distinção, o intelecto é reservado aos anjos, enquanto a razão é própria dos homens. Ora, Agostinho (em De Trinitate XIV, 8, n. 11) cita a inteligência como uma das faculdades humanas em que se realiza a imagem divina e, ao se deparar com esse texto no seu Comentário ao Livro I das Sentenças ${ }^{18}$, Tomás de Aquino se dá conta de uma dificuldade: o ser humano possui razão ou intelecto?, ou, dito de outra forma, qual a natureza da razão humana? ${ }^{19}$; a resposta a essa dificuldade é uma verdadeira elaboração de elementos distintos que permite, segundo Peghaire, "assistir ao vivo o trabalho aristotelizante de Tomás ${ }^{20}$ ", já que é em torno do texto de Aristóteles que os distintos elementos serão sintetizados.

Os elementos são os seguintes: a) do Pseudo-Dionísio, Tomás adota o princípio de hierarquia dos seres por contiguidade, em que o inferior toca, pelo que nele é mais elevado o que é inferior do imediatamente superior, bem como a ideia mesma da distinção entre a natureza intelectual e a racional ${ }^{21}$; b) de Agostinho, ele conserva a ideia de que é por sua parte mais alta e perfeita que a alma humana é imagem da Trindade; c) de Aristóteles, ele toma a conclusão que expõe a diferença entre a razão, que

16 "Tercius vero actus rationis est secundum id quod est proprium rationis, scilicet discurrere ab uno in aliud, ut per id quod est notum deveniat in cognitionem ignoti; huic desrviunt reliqui libros logice" (AQUINO, 1989, I, 1, 46-49).

${ }^{17}$ Apoiamo-nos, nessa parte, na nota de Gauthier ao texto da edição Leonina (p. 4-5), em que se pode encontrar as referências completas quanto ao percurso dessa distinção no pensamento medieval.

18 Distinção 7.

${ }^{19}$ Cf. PEGHAIRE, J. Intellectus et ratio selon S. Thomas d'Aquin, Paris: Librairie Philosophique J. Vrin, 1936, p. 32-33.

${ }^{20}$ PEGHAIRE, 1936, p. 32-33.

${ }^{21}$ Cf. MONTAGUE, B. L'axiome de continuité chez saint Thomas d'Aquin, Revue des Sciences Philosophiques et Theologiques, Paris, v. 62, p. 173-221, 1968. 
conhece a custa de pesquisas e no tempo e o entendimento ou inteligência, que conhece sem intermediários e que, no ser humano, tem por objeto os primeiros princípios; d) de Isaac Israeli, ele retém a fórmula "natura intellectualis obumbrata" para designar a razão, fórmula também de inegável teor neoplatônico e que ajuda a reafirmar a idéia de que "a razão nada mais é do que a natureza intelectual obscurecida".

A síntese desses elementos, que se acha no tratamento de uma questão do Primeiro Livro das Sentenças (In Primum Sententiarum, d. 3, q. 4, ad 4) em que ele acaba por conciliar uma ideia de origem neoplatônica, segundo a qual há uma hierarquia entre os seres e nesta hierarquia há um intermediário entre o homem e Deus, isto é, o anjo, com a ideia de origem aristotélica que distingue as várias operações intelectuais ${ }^{22}$.

Não se trata de ver, como veremos mais adiante, o espírito humano como imperfeito em relação ao intelecto angélico, que se apresentaria como um modelo ideal. De fato, a natureza própria do homem, dentro da hierarquia das criaturas, só lhe permite conhecer dessa maneira; enquanto o anjo conhece tudo segundo a essência num só ato, o ser humano só chega a entender algo após um processo de abstração. $\mathrm{O}$ anjo, por ser hierarquicamente superior, permite entender a nossa verdadeira capacidade de conhecer por comparação com esse poder superior; é só nesse sentido que o conhecimento angélico atua como um modelo ideal. Quanto ao nosso intelecto, só algumas poucas verdades se nos apresentam em sua absoluta simplicidade e evidência; é o que se chama o entendimento no homem, a inteligência dos primeiros princípios.

Quando Tomás de Aquino diz, no texto da Expositio, que as duas primeiras operações pertencem à razão enquanto esta é certo intelecto ${ }^{23}$, ele associa essas duas operações à noção de "intellectus", que apreende o

${ }^{22}$ MONTAGUE, 1968, p. 173-221. Pode-se encontrar algo de semelhante, quanto ao uso de Dionísio, Agostinho e Aristóteles na Suma de Teologia, $1^{\mathrm{a}}$ parte, q. 84. Cf. NASCIMENTO, C. A. R. do. As auctoritates na questão 84 da $1^{\text {a }}$ parte da Suma de Teologia. In: Soares, A. G. T. de; Tannús, M. C.; Seneda, M. C. (Org.). Suma de Teologia, parte I, questões 84 a 89. Tradução e introdução: Carlos Arthur Ribeiro do Nascimento. Uberlândia: EDUFU, 2005.

23"Quorum primi duo sunt rationis secundum quod est intellectus quidam" (AQUINO, 1989, I, 1, p. 34-35). 
indivisível (no que não há verdadeiro/falso) e combina esses indivisíveis. A terceira operação é propriamente a da razão, o discurso que passa do conhecido ao ignorado.

A natureza dupla do homem (corpo e alma) não lhe permite que seu intelecto conheça diretamente as essências. Pelo contrário, a inteligência dos indivisíveis bem como a composição e divisão estão vinculadas ao conhecimento sensível e, além disso, a composição/divisão operada a partir daqueles está longe da garantia de ser sempre verdadeira. A razão apresenta-se assim como o caráter distintivo do homem, como o trabalho de abstrair os universais a partir dos singulares apreendidos pelos sentidos, de obter conhecimento novo a partir do que já é sabido.

No entanto, parece inteiramente possível que se enquadre a razão discursiva como um tipo especial da segunda operação, mantendo assim o quadro tradicional aristotélico em que são distintas apenas duas operações do espírito; pode-se falar de uma composição ou divisão imediata (SP) ou mediata (S-TM-P) ${ }^{24}$, sendo ambos casos composição ou divisão. A introdução da terceira operação não é a única via para se justificar a tripartição da lógica em lógica dos termos, das proposições e do raciocínio (correspondendo respectivamente à $1^{\mathrm{a}}, 2^{\mathrm{a}}$ e $3^{\mathrm{a}}$ operações do espírito acima mencionadas): bastaria considerar as duas formas da composição e divisão.

Na verdade, a introdução do raciocínio como uma terceira operação do espírito é um reflexo da oposição intelecto-razão, como podemos concluir a partir da leitura (Exp. Lib. Post. I, 1 lin. 34-49: "as duas primeiras pertencem à razão enquanto esta é um certo intelecto..." e "o terceiro se dá de acordo com aquilo que é próprio da razão, isto é, discorrer a partir de um até algo de outro, de modo que a partir do que é conhecido, cheguemos ao conhecimento do ignorado") . Por essa oposição, o intelecto humano se distingue do intelecto angélico.

Como dissemos, o texto que examinamos é um dos dois únicos lugares, na obra de Tomás, onde se fala das três operações do espírito.

\footnotetext{
${ }^{24}$ A composição do tipo S-P (Sujeito - Predicado) é uma proposição predicativa simples (por exemplo, "Homem é mortal”), a composição do tipo S-TM-P (Sujeito Termo Médio - Predicado) seria um silogismo, em que dois termos são unidos pelo termo médio (por exemplo, "Homem é mortal, grego é homem; grego é mortal").
} 
Trata-se quase de uma licença que Tomás se permite, e que ele justifica no comentário ao Peri Hermeneias ${ }^{25}$ como um acréscimo ou um modo da segunda operação. Não obstante, em algum momento na história do tomismo, ela se tornou padrão e os manuais de lógica de inspiração tomista (ad mentem sancti Thomae) falam correntemente em três operações do entendimento, sem se importar que de fato, nas origens desta divisão, só há duas ${ }^{26}$.

Enquanto as Categorias e o Peri Hermeneias abordam respectivamente aqueles elementos indivisíveis e a combinação simples entre eles (formação de proposições), o conhecimento propriamente humano precisa ser construído segundo a razão discursiva, que é o de que se ocupam, de acordo com Tomás de Aquino, os demais livros do Organon, segundo as três possibilidades examinadas a seguir.

\section{Ars Imitatur Natura}

Os atos da razão, aqui entendida como a terceira operação do espírito $^{27}$, assemelham-se aos processos da natureza, obedecendo ao

${ }^{25}$ In Peri Hermeneias, $I, 1$.

${ }^{26}$ Cf. MARITAIN, J. Elementos de filosofia II: lógica menor. Rio de Janeiro: Agir, 1962. Maritain organiza esse manual em três capítulos, cada um dos quais se dedica a uma das operações do espírito; diz ele: “o raciocínio, como já sabemos, é a terceira operação do espírito” (p. 155). Veja também: GARDEIL, H. D. Initiaton a la philosophie de Saint Thomas d'Aquin, Paris: Editions du Cerf. 1956. GREDT, J. Elementa philosophiae aristotelico-thomisticae, In: ___. Logica et philosophia naturalis. Roma: Herder, 1961. v.1.

${ }^{27}$ Há, no texto que estamos apresentando, o uso de uma terminologia pouco rigorosa ou sistemática, que se presta a confusões. De fato, em primeiro lugar, Tomás escreve: "É preciso que as partes da lógica sejam tomadas segundo a diversidade dos atos da razão. Ora, os atos da razão são três” (AQUINO, 1989 Exp. Lib. Post. I, I, 1, 32-34). Denomina em seguida as duas operações do intelecto conforme o texto do De Anima In Sent. Lib. De Anima (AQUINO, 1984, v,3). Mais adiante, a respeito da semelhança entre os atos da natureza e os atos da razão, ele escreve: "essas três diferenças ocorrem também aos atos da razão" (AQUINO, 1989, Exp. Lib. Post. I, p. 64-65) e apresenta em seguida os três modos diversos segundo os quais a razão age. De modo que é preciso estar atento para não confundir as três operações do espírito (Inteligência dos indivisíveis, Composição/divisão e Discurso racional) com os três processos da razão. 
princípio segundo o qual a arte imita a natureza. Nos processos da natureza, Tomás identifica uma tríplice modalidade. Na verdade, há duas duplas de modalidade. Em primeiro lugar, há a seguinte distinção: em certos processos, a natureza age necessariamente, isto é, nunca ocorre falha e em certos outros a natureza não age necessariamente, mas de modo contingente. No segundo caso, uma nova distinção se observa: há aqueles processos em que o resultado acontece geralmente ou mais frequentemente (ut in pluribus) e os processos em que, devido a alguma falha nos princípios, o resultado não ocorre. $\mathrm{O}$ exemplo esclarecedor é o seguinte: a partir do sêmen, no mais das vezes, é gerado um animal perfeito; mas pode ocorrer alguma falha e ser gerado um monstro.

A analogia com os processos da razão é a seguinte. Há um processo da razão que conduz a uma verdade necessariamente; por meio dele adquirimos a certeza da ciência. Há também um segundo processo, que no mais das vezes conduz a conclusões verdadeiras, mas não necessariamente. Mas há também os casos em que a razão falha em virtude da inobservância de algum preceito no ato de raciocinar e a conclusão a que este conduz não é verdadeira.

A cada um desses três processos dedica-se uma das partes da lógica. A parte que é dedicada ao primeiro processo é chamada judicativa, tendo em vista nela tratar-se do juízo dotado de certeza; ora, sendo, o juízo certo sobre os efeitos possível, apenas com um retorno (resolutio) aos primeiros princípios, tal parte também se denomina Analítica, isto é, Resolutória. Além disso, a certeza do juízo obtido por resolução ou provém apenas da forma do silogismo ou provém da forma e da matéria, que são as proposições por si e necessárias. Os escritos sobre o silogismo pura e simplesmente se denominam Primeiros Analíticos. Os Segundos Analíticos tratam do silogismo demonstrativo ou científico.

$\mathrm{O}$ segundo processo da razão cabe à parte da lógica chamada inventiva, em que o grau de certeza de suas conclusões varia conforme se aproximem mais ou menos da certeza perfeita. Essa parte da lógica é assunto do livro dos Tópicos, que trata dos silogismos dialéticos que utilizam proposições prováveis, produzindo crença ou opinião. $\mathrm{O}$ que caracteriza a estas é que, embora não haja a certeza científica, a razão adere firmemente a uma das partes da contradição, mas considerando que a outra parte também 
pode ser verdadeira. Os livros da Poética e da Retórica também são dedicados aos atos da razão que não chegam a atingir a certeza, mas dela apenas se aproximam. A Retórica trata dos argumentos que utilizam proposições que não buscam produzir opinião, mas certa suspeita (suspicio quedam), isto é uma adesão não tão firme a uma das partes da contradição e a Poética trata dos argumentos que buscam inclinar a uma certa estima (estimatio) por meio de uma representação, como quando se provoca a abominação por uma comida, representando-a em termos abomináveis. O que há de comum entre esses livros é que "todos pertencem à filosofia racional, com efeito, levar (do conhecimento) de um a outro é próprio da razão"28.

Quanto ao último processo, a ele corresponde a parte em que se analisam os possíveis erros nas argumentações, sendo chamada de Sofística, apresentada no livro dos Elencos ou Refutações Sofisticas.

Após essa exposição da estrutura da lógica, correspondente à estrutura da própria razão, é que Tomás apresenta a intenção ou função dos Segundos Analíticos. Este escrito pertence, com efeito, à parte da lógica chamada judicativa, na qual se estudam os atos ou processos da razão que conduzem à verdade certa, isto é, à ciência.

Os Segundos Analíticos tratam do silogismo demonstrativo, também chamado de silogismo científico, pois por ele se adquire ciência, isto é conhecimento necessariamente verdadeiro. Daí a divisão que Tomás propõe do texto aristotélico: na primeira parte mostrará a necessidade do silogismo demonstrativo (livro I, capítulos 1 a 3) e, em seguida, determinará os seus caracteres essenciais (capítulos 4 a 44 do livro I). $\mathrm{Na}$ segunda parte, discorrerá sobre os princípios a partir dos quais procede o silogismo demonstrativo (no livro II).

\section{Lógica e ciência}

O texto do prólogo da Expositio permite-nos formular uma dúvida, cuja solução mostraria com mais clareza a natureza da lógica: afinal, a lógica é ciência ou arte? Como vimos, após argumentar pela necessidade

28 "Omnia autem hec ad rationalem philosophiam pertinent:inducere enim ex uno in aliud rationis est" (AQUINO, 1989, Expositio libri Posteriorum I, 1, 118-120). 
de uma arte que dirigisse a própria razão, Tomás indica: “esta arte é a lógica, isto é a ciência racional" 2 .

Se considerarmos certos textos dos comentários aristotélicos de Tomás de Aquino, como o dedicado a uma conhecida passagem do livro VI, da Ética à Nicômaco ${ }^{30}$, veremos que a dúvida procede. Afinal, conforme esse texto, arte e ciência são habilitações distintas do intelecto. Ambas relacionam-se de modo diverso com a verdade das coisas, a arte no âmbito do que é contingente e a ciência no âmbito do necessário. Além disso, da arte resulta sempre um certo produto, fruto de um trabalho humano dirigido pela razão; enquanto o resultado da ciência teórica é um puro conhecimento.

Uma primeira solução para essa divergência entre os textos seria simplesmente considerar que Tomás não utiliza no prólogo do Comentário aos Segundos Analíticos uma terminologia muito rigorosa e toma arte e ciência como sinônimas. O próprio Aristóteles parece proceder dessa maneira no livro A da Metafisica, ao estabelecer os diversos graus de conhecimento, sensação, memória, experiência e arte e dividindo a arte em três grupos; as necessárias à sobrevivência (práticas), as prazerosas e as teóricas, cuja finalidade é simplesmente o saber ${ }^{31}$. Embora não se possa

${ }^{29}$ AQUINO, 1989, I, 1, p. 17-25.

${ }^{30}$ Aristóteles. Ética a Nicômaco, VI, 3.(1139b, p. 15-35), texto em que Aristóteles remete o leitor aos Segundos Analíticos. Esse texto é comentado por Tomás: Sententia libri Ethicorum, VI, 3. Roma ad Sanctae Sabinae, 1969, tomo 47, volume 2 (edição Leonina)

${ }^{31}$ Aristóteles. Metafísica A, 1 980a21-981b25. Tradução de David Ross: “as more arts were invented, and some were directed to the necessities of life, other to its recreation, the inventors of the later were always regarded as wiser than the inventors of the former, because their branches of knowledge not aim utility. Hence, when all such arts were already established, the sciences which do not aim at giving pleasure or at the necessities of life were discovered, and first in the places were men first began to have leisure. This is why the mathematical arts were founded in Egypt, for there the priestly caste was allowed to be at leisure". Cf. ROSS, D. (Ed.).Metaphysics. Oxford: Clarendon Press, 1997. , edição e comentário de David Ross. No comentário a este trecho, Ross diz que Aristóteles tem em vista uma divisão tripartida das technai: as artes úteis, as belas artes e as artes teóricas ou ciências (p. 118, grifo nosso). Também na tradução de Warrington vemos o uso de arte como sinônimo de ciência, isto é, um uso não rigoroso do termo. Cf. Aristotle, Metaphysics, Tradução e comentário de 
descartar inteiramente essa solução, é preciso admitir que, nesse ponto, Tomás também está aludindo a uma dupla natureza da lógica, que devemos considerar mais de perto ${ }^{32}$.

A lógica como arte é o instrumento para o pensamento correto. Munido do conhecimento sobre as regras do funcionamento de sua razão, o homem estaria apto a discorrer nos diversos domínios do conhecimento, especialmente nas ciências, produzindo os argumentos, que seriam verdadeiros "produtos" dessa arte. Podemos lembrar, quanto a esse ponto, uma passagem do Comentário ao De Trinitate de Boécio, em que Tomás responde um argumento contrário à divisão tripartida das ciências teóricas (Física, Matemática e Metafísica ou Teologia). O argumento, o terceiro de uma lista de dez, opõe à divisão apresentada à divisão tradicional das sete artes liberais (o trivium: gramática, retórica e lógica e o quadrivium: aritmética, geometria, astronomia e música). Em sua resposta, Tomás determina o caráter de arte dessas disciplinas contrapondo-as seja às artes mecânicas, seja às ciências teóricas, esclarecendo que essas artes "implicam não só conhecimento, mas uma certa obra que procede imediatamente da razão, como uma construção gramatical, a formação de um silogismo ou de um discurso, enumerar, medir, compor uma melodia ou calcular o curso dos astros" "33. Tal é o conceito de "arte liberal", a qual é arte porque algo é produzido com a aplicação da razão, mas é livre, isto é não procura atender a uma necessidade prática material de sobrevivência ${ }^{34}$.

Warrington, John. [1956], Londres/Nova York: J.M. Dont \& Sons/ E.P. Dutton \& Co., p. 51, nota 4. Também Angioni [2009], em sua tradução, equipara a arte teórica e a ciência: "quando todas as técnicas desse tipo estavam já constituídas, foram inventadas as ciências que não são voltadas nem ao prazer nem à necessidade... as técnicas matemáticas foram inventadas no Egito..."

${ }^{32}$ Cf. SCHMIDT, R. The domain of logic according Saint Thomas Aquinas, The Hague: Martinus Nijhoof, 1960.

${ }^{33}$ AQUINO, T. de. Comentário ao Tratado da Trindade de Boécio. Questão 5, artigo 1, ad 3um, São Paulo: Unesp, 1998. p. 105.

${ }^{34}$ É impossível entrar aqui em detalhes sobre a longa e complexa história do quadro das artes liberais. Para uma ampla abordagem, ver, entre outros: Arts liberaux et Philosophie au Moyen Âge, Actes du quatrieme Congrés International de philosophie medievale, Université de Montreal, Canadá,Institut d' Etudes Medievales, 20/802/9/1967, Paris: Vrin, 1969. 
A classificação da lógica como arte liberal situa a primeira de suas duas definições. Vejamos como se pode considerar a lógica como ciência. Segundo a classificação das ciências adotada por Tomás de Aquino, há dois tipos de ciências: as especulativas ou teóricas e as práticas. As ciências especulativas resolvem-se naquela divisão tripartida, já aludida, no Comentário ao De Trinitate: física, matemática e metafísica. Aí não parece haver lugar para a lógica, que é exatamente o espírito do argumento relembrado acima.

Quanto às ciências práticas, elas podem ser produtivas ou ativas. Aqui também não parece haver lugar para a lógica, uma vez que as ciências práticas produtivas equivalem às artes mecânicas, cujo resultado é um produto material utilizável de algum modo ${ }^{35}$ e as ativas têm a ver com a vontade, uma vez que o princípio de ação e a escolha é um ato de vontade, não de razão exclusivamente: as ciências práticas ativas sendo então a moral, a economia (governo da casa) e a política.

O impasse a que se é conduzido pela consideração desse quadro só pode ser resolvido encontrando nele um lugar especial para a lógica ${ }^{36}$. Com relação às ciências desse quadro, a lógica é introdutória, uma vez que dela depende em seu ordenamento, o conhecimento de uma ciência; é, por isso mesmo, instrumental na elaboração, no aprendizado e desenvolvimento das ciências, pois trata do modo de proceder nas ciências, razão pela qual deve ser aprendida em primeiro lugar ${ }^{37}$.

A lógica tem seu lugar à parte, mas isso não significa que ela deva se opor ou se separar radicalmente das outras ciências. Significa apenas que, em certo sentido ela é prática, é arte, e em certo sentido é especulativa, é ciência, sendo o seu fim teórico buscar a verdade a respeito dos produtos da razão e seu fim prático guiar a mesma razão na formação desses produtos. Desses dois fins, prevalece o fim especulativo, o que permite retificar o quadro anterior para incluir a lógica entre as ciências especulativas, o que pode ser assim visualizado:

\footnotetext{
${ }^{35}$ A esse propósito, há a expressão recta ratio factibilium, "a correta execução das coisas factíveis" como definição de arte, atividade produtiva. Cf. SCHMIDT, 1966. p. 4.

${ }^{36}$ Cf. SCHMIDT, 1966, p. 24-37.

${ }^{37}$ Cf. AQUINO, T. de. Comentário ao Tratado da Trindade de Boécio. Questão 5, artigo 1, ad 3um, São Paulo: Unesp, 1998.
} 


\section{Especulativas \\ Racionais (Lógica)}

Reais (Física, Matemática, Metafísica)

Ciências
Ativa
(Ética, Política)

Práticas

Produtiva (Artes mecânicas $=$ técnicas $)$

Note-se que, considerada como ciência, a lógica tem por sujeito, isto é, por assunto de estudo, não entes reais, mas entes racionais, produtos da razão humana e por isso não é uma ciência real, isto é, sobre as coisas. Vemos, nesse quadro, a solução básica adotada por Tomás, que não entra em conflito com o quadro tradicional nem com a classificação apresentada no Comentário ao De Trinitate. Vemos também que nesse quadro considera-se a ciência num sentido mais amplo do que aquele presente na exposição dos Segundos Analíticos, que se refere mais à ciência teórica. Podemos falar, a partir dessas considerações também numa lógica pura, que estudaria as intenções ou noções lógicas e suas relações e numa lógica aplicada, que faz uso deste estudo para conduzir as operações da razão, o que refletiria a dupla natureza da lógica como ciência (pura) e arte (aplicada). Quanto ao seu uso, a lógica é uma ciência quasi factiva, isto é, arte; quanto à doutrina é uma arte quasi speculativa, isto é ciência.

Tendo as intenções ou noções lógicas como sujeito, isto é, como seu tema de estudo, e visto que essas intenções comandam o exercício de nossa razão quanto ao conhecimento, em especial quanto à ciência, a lógica adquire um caráter geral que a torna muito semelhante à metafísica, na medida em que ambas são universais, partem de princípios comuns a todas as coisas, estudam os contrários e tratam do verdadeiro e do falso. Diferem, porém, na medida em que a metafísica é ciência dos entes reais e a lógica, dos entes de razão; a metafísica desvenda a estrutura do mundo real e a lógica, a do mundo pensado, a metafísica aborda o que é referido pelas proposições a modo de ser, a lógica considera o modo de predicação ${ }^{38}$.

${ }^{38}$ Cf. AQUINO, T. de. Comentário ao Tratado da Trindade de Boécio. Questões 5 e 6. São Paulo: Unesp, 1998. p. 20-21. As intenções lógicas, que Tomás de Aquino 


\section{O intelecto/espírito humano e a ciência}

Abordemos agora um último tema ensejado pela leitura do prólogo da Expositio. Trata-se da possibilidade e dos limites do entendimento humano dentro do quadro da distinção "intellectus/ratio". Podemos tomar como estabelecido, a partir do que já vimos, que a razão é a faculdade propriamente humana, o modo como o homem conhece intelectualmente, e que tem como trabalho prévio, a percepção pelos sentidos. O intelecto humano é situado como uma pálida realização do verdadeiro intelecto cognoscente, que é o intelecto angélico. O ser propriamente intelectual é o anjo, ou a inteligência separada, isto é, um intelecto subsistente em si mesmo e não acompanhado de um corpo composto de elementos do mundo sublunar como o nosso. O intelecto humano tem seu papel de intelecto muito reduzido (o que se refere aos primeiros princípios) e a maior parte do seu conhecimento deve ser obtida num laborioso trabalho de descoberta e aprendizado.

Vimos também que essa distinção, no homem, de duas faculdades, a razão e o intelecto, tem origem neoplatônica e o que Tomás, em seu esforço de síntese, nos transmite não deixa de ser um "platonismo via Aristóteles" 39 ou, se se quiser, um Aristóteles neoplatonizado. Correndo o risco de excessiva simplificação, podemos dizer que Tomás de Aquino trabalha em dois eixos, um transcendental e outro categorial. No eixo transcendental (vertical), referente à relação entre o mundo e Deus, servese dos conceitos provenientes da tradição neoplatônica, via Dionísio, Agostinho e Livro das Causas. No eixo categorial (horizontal), referente à estrutura interna do mundo, serve-se do arsenal conceitual aristotélico.

A complexa relação entre intelecto e razão que se constitui no modo propriamente humano de conhecer é o que Gilson caracteriza da

\footnotetext{
denomina secunda intellecta (noções de segunda ordem), são conceitos sobre conceitos e não sobre coisas. Os exemplos mencionados por ele são: gênero, espécie, definição, oposto, predicado, silogismo, etc.

39 Tomamos essa expressão de empréstimo ao prof. Francisco Benjamin S. Netto, que a utiliza na Introdução à edição de Tomás de Aquino (NETTO, F. B. S. O ente e a essência. Tradução de Carlos Arthur Ribeiro do Nascimento. Petrópolis: Vozes, 1996. edição bilíngue), p. 8.
} 
seguinte maneira, no sexto capítulo de sua principal obra sobre Tomás de Aquino: "o intelecto é a potência que constitui a alma humana em seu grau de perfeição; e, contudo, a alma humana não é, para falar propriamente, um intelecto" 40 .

O anjo é, dentre as substâncias imateriais criadas, aquele que verdadeiramente merece o nome de intelecto ou inteligência, a alma humana, por sua vez, deve desempenhar, com relação ao corpo que anima, funções vegetativas e sensitivas; assim, o intelecto é, propriamente falando, uma das potências da alma, aquela potência pela qual ela se comunica com a realidade que lhe é hierarquicamente superior, a inteligência angélica.

Por sua natureza finita de entes criados, todo intelecto está em potência em relação a toda realidade inteligível diferente de si, todo intelecto é então passivo em relação aos inteligíveis. Mas assim como há uma matéria criada, como a matéria dos corpos celestes, em que a potência jamais se acha privada de seu ato, por isso ela é incorruptível, embora não seja eterna e, por outro lado, há uma matéria, a matéria do mundo sublunar, em que a potência é às vezes privada de seu ato e deve passar de potência a ato para possuí-lo, e tal matéria é corruptível, assim também se relacionam o intelecto angélico e o humano: o anjo, por sua proximidade à Causa Primeira, que é ato puro, possui sempre em ato suas espécies inteligíveis, a alma humana, por sua vez, por ser a última na ordem dos intelectos, é passiva em relação aos inteligíveis não apenas no sentido em que os recebe em si, mas também no sentido em que é naturalmente desprovida deles ${ }^{41}$.

Mas a própria capacidade de inteligir algo, isto é, perceber a forma universal e imaterial presente nos entes materiais, supõe uma atividade do intelecto ou um intelecto ativo ou ainda um intelecto em ato. Uma vez que

as naturezas, isto é, as formas que nosso intelecto conhece nas coisas sensíveis devem ser tornadas inteligíveis em ato e uma vez que só

\footnotetext{
${ }^{40}$ GILSON, E. Le thomisme: introduction à la philosophie de Saint Thomas D'Aquin, Paris: Vrin, 1947. p. 263. Esse capítulo, em que Gilson mobiliza todos os principais textos em que Tomás trata dos diversos aspectos da problemática do conhecimento humano, é certamente uma das melhores apresentações de conjunto sobre o tema que se pode desejar.
}

${ }^{41}$ Idem, ibidem, p. 264. 
um ser em ato pode tornar em ato o que está em potência, o intelecto humano, é preciso atribuir ao intelecto uma virtude ativa que torna inteligível em ato o inteligível que a realidade sensível contém em potência ${ }^{42}$.

Na questão 79 da Suma de Teologia, bem como no comentário ao De Anima ${ }^{43}$, Tomás de Aquino argumenta a favor da unidade do intelecto humano, isto é, da existência, na alma de cada ser humano dessas duas capacidades.

Ora, o que vem a ser a intelecção? É a simples apreensão da verdade inteligível. Já o raciocínio é o movimento do pensamento que vai de um objeto de conhecimento a outro a fim de atingir a verdade inteligível. O raciocínio está para a intelecção assim como o movimento está para o repouso, e assim como o repouso se acha nos dois limites do movimento, do ponto em que ele parte ao ponto em que ele se encerra, assim também a intelecção se acha no princípio e no fim do processo de raciocínio. E se o raciocínio ou razão discursiva é o modo próprio do conhecimento humano, esse modo supõe a intelecção como seu ponto de partida e de chegada. O conhecimento humano parte, portanto, da intelecção dos primeiros princípios e retorna a eles para atingir a certeza. Por esse modo, é que a alma humana, inferior às substâncias intelectuais criadas, participa em seu modo de conhecer.

Isso não se deve, como a opinião platônica supunha, em virtude de uma imperfeição da alma ou mesmo de um castigo que ela tenha sofrido e pelo qual ela está unida a um corpo que a impede de conhecer. Tomás considera mesmo chocante que a natureza, que fez a alma para conhecer, a tenha unido a um corpo que a impeça de conhecer. Pelo contrário, se a alma humana é naturalmente unida a um corpo, isso só deve significar que esse corpo é necessário para que o conhecimento intelectual seja possível ${ }^{44}$. $\mathrm{O}$ processo de abstração é justamente o processo pelo qual a alma humana, com a ajuda dos sentidos, torna inteligível a realidade sensível.

\footnotetext{
${ }^{42}$ Idem, ibidem.

${ }^{43}$ Summa Theologia, I, q. 79, 2, ad Resp; Sent. Libri De Anima, qu, un, art 5, Resp.

${ }^{44}$ GILSON, 1947, p. 270. Cf. AQUINO, 1926, I, 89, 1 ad Resp.
} 
Dos três processos do espírito humano, os dois primeiros relacionamse com a intelecção, na medida em que a alma humana pode dela participar, trata-se da intelecção dos primeiros princípios e das quididades que formam o material do conhecimento. O terceiro processo, a razão discursiva, é o que caracteriza propriamente o modo de conhecer humano; tendo como ponto de partida uma capacidade de intelecção, só pode progredir, no entanto, por meio de um laborioso processo, nem sempre infalível pelo qual se passa do conhecido ao ignorado. Esse é o trabalho principal da lógica, como arte das artes, nos orientar nesse processo de modo a que não falhemos nessa passagem, na medida em que isso é possível. E como ciência, é o estudo das regras que constituem essa arte de modo que tais regras sejam apreendidas como verdadeiras e necessárias. A possibilidade do conhecimento humano repousa no sucesso desse empreendimento.

Como nossa natureza é dupla, no que temos de não material participamos também daquele conhecimento imediato. Trata-se da inteligência dos primeiros princípios, como dissemos; é pouco, mas sem isso não poderia sequer haver a ciência que tão arduamente podemos conquistar com o uso de nossa razão ${ }^{45}$.

Que ciência é essa? Que esperança temos de adquirir certezas evidentes a respeito do mundo que nos cerca? Como podemos ter certeza da certeza desse conhecimento? Enfim, qual é o âmbito desse conhecimento?

É justamente sobre as condições que devem ser satisfeitas, no desenvolvimento do raciocínio, a fim de que se obtenha uma certeza

${ }^{45} \mathrm{O}$ tema aqui assinalado, o é apenas assinalado. Desenvolvê-lo em detalhe desviaria do objetivo próprio do presente trabalho. A bibliografia sobre o conhecimento intelectual humano segundo Tomás de Aquino é enorme. Ver, por exemplo, ROBERT, J. D. Elements de Bibliographie pour l'étude du problème de la conaissance, Revue Philosophique de Louvain, Paris, v. 56, p. 586-604, 1958. Para alguns detalhes sobre as características do conhecimento intelectual humano, segundo Tomás de Aquino, ver, entre outros: NASCIMENTO, C. A. R. do. Las quaestiones de la primera parte de la Suma de Teologia de Tomás de Aquino. In: BERTELLONI, F.; BURLANDO, G. La filosofia medieval. Enciclopedia Iberoamericana de filosofia, Madri: Editorial Tratto, Consejo Superior de Investigaciones Científicas, 2002, p. 157-177. v. 24. Esta postura de Tomás de Aquino cria problemas razoavelmente complicados para mostrar como a alma separada do corpo, após o desaparecimento deste com a morte, pode conhecer. Cf. AQUINO, 2004, I' parte, q. 89. 
apodíctica, isto é, científica em sentido estrito, que se detém o comentário aos Segundos Analíticos, que Tomás passa a expor em seguida.

\section{Conclusão}

A apresentação geral e esquemática da lógica como disciplina feita no prólogo da Expositio Libri Posteriorum, de Tomás de Aquino, parece obedecer a dois critérios: 1) a ordem das operações do espírito humano, cuja natureza se depreende por comparação a um modelo ideal, o intelecto angélico e a um modelo inferior, os animais inferiores; 2) a disposição das obras que compunham o Organon aristotélico tal como era conhecida na época de Tomás (e que até hoje é conhecida como a ordem tradicional dos escritos do Filósofo, sendo a ordem em que se encontra na edição standard de Bekker).

Quanto ao primeiro critério, vimos que, graças a sua natureza peculiar, sua composição de uma parte material, o corpo e uma parte espiritual, a alma, o homem é capaz de transcender a mera apreensão dos caracteres sensíveis do mundo exterior e formular juízos com sua razão. É por meio de sua capacidade racional que o ser humano age nesse mundo e, ultrapassando o mero instinto, consegue viver de modo mais seguro e confortável que os animais, isto é, descontando-se os danos que os seres humanos podem causar uns aos outros justamente por serem racionais, podemos assumir que, pelo menos, não estamos cegamente submetidos à natureza. Nem se trata aqui de saber se isso é melhor ou pior para nós, se é ou não um castigo para o ser humano estar sujeito a essa realidade, trata-se apenas de constatar que essa é a ordem da natureza: o ser humano, como todos os animais, apreende a realidade que o cerca por meio dos seus sentidos, mas diferente dos animais, ultrapassa a mera apreensão e produz juízos sobre a realidade; ora, essa capacidade se deve a parte espiritual da natureza humana.

A dependência dos sentidos impede que o ser humano conheça as coisas do mundo exterior diretamente em suas essências, ele precisa abstrair tais essências por meio de um trabalho intelectual, que é natural do ser humano. Qualquer pessoa, mesmo uma criança, ao identificar algo ou distinguir algo, está utilizando-se de sua capacidade de abstração. É o modo natural do conhecimento humano. A dependência para com o corpo e nossos sentidos, no entanto, faz com que o nosso conhecimento sobre o mundo 
esteja sempre em suspenso, o abismo entre sentidos e intelecto impede que tenhamos um conhecimento absolutamente certo da realidade que nos cerca.

Exceto, talvez, por uma pequena parte de nosso conhecimento que é a apreensão dos primeiros princípios, ou princípios autoevidentes, sem os quais, aliás, não poderíamos formular quaisquer conhecimentos sobre o mundo, eles estão na base de nossa atividade racional. A apreensão desses primeiros princípios é o que se chama propriamente o intelecto no ser humano.

Com base no intelecto e na capacidade racional, o conhecimento humano do mundo que nos cerca se dá, em sua maior parte, por raciocínio, isto é, a razão discursiva, a capacidade de passar do conhecido ao ignorado, a terceira operação de nosso espírito. As outras duas operações, a simples apreensão e a composição/divisão são ligadas mais ao intelecto, à capacidade de apreender de modo não discursivo, da qual temos apenas um vislumbre e, ainda assim na dependência dos sentidos, mas que nos anjos é plena, dispensando-os da razão discursiva.

Com relação ao segundo critério, Tomás de Aquino entende a obra lógica de Aristóteles como definitiva. Tudo o que é possível saber ou que é preciso saber a respeito do modo de operação de nossas faculdades cognitivas foi tratado pelo filósofo em suas obras lógicas, cujo conjunto conhecemos como Organon.

\section{Referências}

\section{Tomás de Aquino}

AQUINO, T. de. Opera Omnia iussu Leonis XIII P.M. edita, Roma/Paris: Comissio Leonina/ Librairie Philosophique J. Vrin, editio altera retractata, cura et studio Fratrum Praedicatorum. Expositio Libri Posteriorum, volume I-2, com prefácio de René Antoine Gauthier, que é o responsável pela edição, 1989.

. Comentario de los Analiticos Posteriores de Aristóteles. Tradução, introdução e notas de Ana Mallea e Marta Daneri-Rebok, 2002.

. Comentário ao Tratado da Trindade de Boécio. Tradução e introdução de Carlos Arthur R. Nascimento.São Paulo: Unesp, 1998. 
. Commentary on Aristotle's Posterior Analytics. Tradução, introdução e comentário de Richard Berquist. Notre Dame/Indiana: Dumb Ox Books, 2007.

. In Aristotelis libros Peri hermeneias et Posteriorum analiticorum expositio. Cura et Studio P. Fr. Raymundi M. Spiazzi, O.P., Turin: Marietti. 1955. . O ente e a essência. Tradução de Carlos Arthur R. do Nascimento, aprensentação de Francisco B. S. Netto. Petrópolis: Vozes, 1995.

. Suma de teologia: [primeira parte - questões 84-89]. Tradução e introdução de Carlos Arthur Ribeiro do Nascimento. Uberlândia: EDUFU, 2004. . Summa theologiae. Curato da P. Caramello. Taurini [Torino], Marietti, 1926 - 6 vols.

\section{Estudo modernos}

GARDEIL, H. D. Initiaton à la philosophie de Saint Thomas d'Aquin. Paris: Editions du Cerf, 1952.

GILSON, E. Le thomisme: introduction à la philosophie de Saint Thomas D’Aquin. Paris: Vrin, 1947.

GREDT, J. Elementa philosophiae aristotelico-thomisticae, In: Logica et philosophia naturalis. Roma: Herder, 1961. v.1.

PEGHAIRE, J. Intellectus et ratio selon S. Thomas d'Aquin, Paris: Vrin, 1936.

SCHMIDT, R. The domain of logic according Saint Thomas Aquinas. The Hague: Martinus Nijhoof, 1966.

TORREL, J.-P.. Iniciação a Santo Tomás de Aquino. Tradução de Luiz Paulo Rouanet. São Paulo: Loyola, 1999.

WEIJERS, O. La Structure des commentaires philosophiques à la faculté dês arts: quelques observations. In: . Il commento filosofico nell'ocidente latino, Turnhout: Brepols, 2002. 


\section{ANEXO A - Tradução do prólogo da Expositio libri Posteriorum, de Tomás de Aquino I, 1, p. 3-7}

Como diz Aristóteles no princípio da Metafisica, o gênero dos homens vive pela arte e pelos raciocínios. Nisso, o Filósofo parece tocar numa certa propriedade dos homens pela qual ele se diferencia dos outros animais: com efeito, os outros animais agem por um certo instinto natural em seus atos, mas o homem, em suas ações, é dirigido pelo juízo da razão, e é daí que, para a realização dos atos humanos de modo fácil e ordenado, foram inventadas as diversas artes: a arte nada mais parece ser do que certa ordem da razão, de modo que os atos humanos atinjam seus devidos fins por meios determinados.

Ora, parece que a razão não somente pode dirigir o ato das partes inferiores, mas também é diretiva com relação aos seus próprios atos: com efeito, é próprio da parte intelectiva que reflita sobre si própria; com efeito, o intelecto intelige a si mesmo e do mesmo modo a razão pode raciocinar sobre seu ato.

Portanto, se do fato de a razão, ao raciocinar sobre os atos da mão, resultou a invenção da arte edificativa ou fabril, por meio das quais o homem de modo fácil e ordenado pode exercer este tipo de ato, pela mesma razão uma certa arte é necessária que seja diretiva do próprio ato da razão, ou seja, (uma arte) pela qual o homem proceda de modo fácil, ordenado e sem erro no próprio ato da razão; e esta arte é a lógica, isto é, a ciência racional. A qual não é racional somente pelo fato de ser segundo a razão, o que é comum a todas as artes, mas pelo fato de ter o próprio ato da razão como de sua matéria própria; e por isso essa parece ser a arte das artes, porque nos orienta quanto aos atos da razão, do qual procedem todas as artes.

Portanto, é preciso considerar as partes da lógica segundo a diversidade dos atos da razão. Ora, os atos da razão são três. Dos quais, os dois primeiros são atos da razão segundo esta é certo intelecto: uma ação do intelecto é, de fato, a inteligência dos indivisíveis ou incomplexos, segundo a qual se concebe o que é a coisa, e esta operação é chamada, por alguns, de informação do intelecto ou imaginação pelo intelecto; e a esta operação da razão se ordena a doutrina que Aristóteles trata no livro das 
Categorias. A segunda operação do intelecto é a composição ou divisão do inteligido, na qual já há verdadeiro e falso; e a este ato da razão se destina a doutrina que Aristóteles trata no livro Sobre a Interpretação (Pery Hermeneias).

Ora, o terceiro ato da razão é segundo o que é próprio da razão, isto é discorrer de um a outro, tal que por aquilo que é conhecido se chegue ao conhecimento do que é ignorado; e a este ato se destinam os outros livros da lógica.

Deve-se notar que os atos da razão são semelhantes em algo aos atos da natureza donde a arte também imita a natureza no que é possível. Ora, nos atos da natureza ocorre uma tríplice diversidade: com efeito, em alguns atos a natureza age por necessidade, de tal modo que não pode falhar; em outros a natureza opera segundo o frequente, às vezes ocorre que possa falhar pelo próprio ato; donde, nesses, há um dúplice ato: um, que é o que ocorre no mais das vezes, assim como quando do sêmen se gera o animal perfeito, acabado, mas há um outro, quando a natureza falha naquilo que é o conveniente, como quando do sêmen se gera algum monstro, em vista da corrupção de algum princípio.

E essas três também ocorrem nos atos da razão: com efeito, algum processo da razão conduz ao necessário, no qual não é possível haver falha quanto à verdade, e por esse tipo de processo da razão se adquire a certeza da ciência; mas há outro processo da razão no qual, no mais das vezes se conclui o verdadeiro, contudo não há necessidade nisso; e há um terceiro processo da razão no qual a razão falha quanto ao verdadeiro, por causa de algum defeito do princípio que devia ser observado ao raciocinar.

Ora, a parte da lógica que serve ao primeiro processo se chama parte judicativa, por que o juízo é a ciência com certeza; e porque o juízo certo sobre os efeitos não pode ser obtido se não se resolvendo nos primeiros princípios, esta parte é chamada de analítica, isto é, resolutória. Ora, a certeza do juízo que é obtida por resolução, o é ou pela própria forma do silogismo apenas, e a isto se ordena o livro dos Primeiros Analíticos, que é sobre o silogismo, pura e simplesmente, ou, além disto, também pela matéria, que é representada por proposições por si e necessárias, e a isto se ordena o livro dos Segundos Analíticos, que é sobre o silogismo demonstrativo. 
Ora, ao segundo processo da razão, serve outra parte da lógica chamada de inventiva: com efeito, nem sempre há certeza na invenção, donde para essas coisas que foram inventadas se requer o juízo para que haja certeza. Mas, como nas coisas naturais, no que ocorre na maioria das vezes, se nota uma certa graduação, porque, quanto mais forte é a virtude da natureza, tanto mais raramente falha quanto ao seu efeito, assim também no processo da razão em que não há completa certeza, ocorre alguma graduação, segundo mais ou menos atinjam a certeza perfeita.

Com efeito, por este tipo de processo às vezes realmente, ainda que não se atinja a ciência, se chega, contudo, à fé ou à opinião, por causa da probabilidade das proposições das quais procede; pois a razão se inclina totalmente a uma parte da contradição, ainda que com receio em relação à outra parte, e a isto se ordena a tópica ou dialética; com efeito, o silogismo dialético é sobre prováveis, do que Aristóteles trata no livro dos Tópicos.

Mas, às vezes não se realiza completamente a fé ou a opinião, mas apenas uma certa suspeita, pois a razão não se inclina totalmente a uma parte da contradição, ainda que se incline mais a esta do que àquela, e a isso se ordena a Retórica.

Às vezes, ainda, somente uma estimativa inclina a uma parte da contradição por causa de alguma representação, assim como se dá a abominação de alguma comida para o homem se a representamos sob a semelhança de algo abominável; e a isso se ordena a Poética, pois o poeta deve induzir a algo virtuoso por meio de uma representação decente.

Ora, todas essas partes pertencem à filosofia racional: com efeito, conduzir de um a outro é próprio da razão.

Mas ao terceiro processo da razão serve a parte da lógica que se diz sofística, da qual Aristóteles trata no livro dos Elencos. Deixadas de lado as outras partes da lógica, pretendemos por ora abordar a parte judicativa, na medida em que é tratada no livro dos Segundos Analíticos. O que se divide em duas partes: na primeira mostra a necessidade do silogismo demonstrativo, sobre o que é este livro; na segunda, que começa em "ora, opinamos que o saber..." (71b9), determina sobre o próprio silogismo demonstrativo.

Data de registro: 04/02/2011

Data de aceite: 16/02/2011 
